\title{
The relationship between anogenital distance and fertility, and genome-wide associations for anogenital distance in Irish Holstein-Friesian cows
}

\author{
M. Gobikrushanth, ${ }^{1,2}$ D. C. Purfield, ${ }^{2}$ J. Kenneally, ${ }^{2}$ R. C. Doyle, ${ }^{2}$ S. A. Holden, ${ }^{2}$ P. M. Martinez, ${ }^{2}$ \\ E. Rojas Canadas, ${ }^{2}$ T. C. Bruinjé, ${ }^{1}$ M. G. Colazo, ${ }^{3}$ D. J. Ambrose,,$^{1,3}$ and S. T. Butler ${ }^{2 *}$ \\ ${ }^{1}$ Department of Agricultural, Food and Nutritional Science, University of Alberta, Edmonton, AB, Canada T6G 2P5 \\ ${ }^{2}$ Teagasc, Animal \& Grassland Research and Innovation Centre, Moorepark, Fermoy, Co. Cork, Ireland, P61 C996 \\ ${ }^{3}$ Livestock Research and Extension Branch, Alberta Agriculture and Forestry, Edmonton, AB, Canada T6H 5T6
}

\section{ABSTRACT}

The evaluation of anogenital distance (AGD), the distance from the center of the anus to base of the clitoris, as a potential fertility trait for genetic selection in dairy cows has generated recent interest. The objectives of this cross-sectional observational study were to (1) characterize the distribution and variability of AGD, (2) determine factors associated with AGD, (3) estimate heritability for AGD, (4) identify single nucleotide polymorphisms (SNP) associated with phenotypic variation of AGD, and (5) validate the relationship between categories of AGD and fertility in Irish Holstein-Friesian cows. Anogenital distance was measured using digital calipers in 1,180 Holstein cows (mean \pm standard deviation: $225 \pm 79 \mathrm{~d}$ in milk) from 10 dairy herds located in Munster, Ireland. In addition, age (yr), weight $(\mathrm{kg})$, height at hip $(\mathrm{cm})$, and body condition score (BCS) at the time of AGD measurement were determined in a subset of 281 cows. Genotype information available from 908 cows was subsequently imputed to the Illumina Bovine High Density BeadChip (Illumina Inc., San Diego, CA) for genome-wide association analysis of phenotypic variation in AGD. Overall, AGD had a normal distribution and high variability (mean \pm standard deviation; $119.2 \pm 11.6 \mathrm{~mm}$ ). Anogenital distance was weakly but positively associated with cow age, hip height, and body weight, and negatively associated with BCS; the phenotypic variation in AGD that was explainable by these variables was small (coefficient of determination; $R^{2}=0.09,0.06,0.10$, and 0.02 , respectively). The estimated heritability for AGD was 0.37 (standard error of mean \pm 0.08 ). Six SNP of suggestive significance were identified on Bos taurus autosomes $6,15,20$, and 26; however, none of these SNP was related to previously identified candidate genes for

Received August 14, 2018.

Accepted October 15, 2018

*Corresponding author: stephen.butler@teagasc.ie fertility. Cows were categorized into quartiles (Q1; 86 to $111 \mathrm{~mm} ; \mathrm{n}=311, \mathrm{Q} 2 ; 112$ to $120 \mathrm{~mm}$; $=330$; $33 ; 121$ to $127 \mathrm{~mm} ; \mathrm{n}=265$, and $\mathrm{Q} 4 ; 128$ to $160 \mathrm{~mm} ; \mathrm{n}=274$ ) based on AGD and the association with reproductive outcomes examined (21-d submission rate, pregnancy to first AI, pregnancy rate within 21, 42 and 84-d after the farm mating start date, and number of times bred). None of the reproductive variables differed significantly between AGD categories. In summary, despite identification of high variability and moderate heritability for AGD in Irish Holstein-Friesian cows, reproductive outcomes did not differ between categories of AGD. This latter result differs from our previous finding of an inverse relationship between AGD and pregnancy outcomes in first- and second-parity Canadian Holstein cows, emphasizing the need to test and validate this new phenotype in diverse cow populations.

Key words: fertility trait, heritability, reproductive efficiency, genomic selection

\section{INTRODUCTION}

Anogenital distance (AGD) has been defined as the distance from the center of the anus to either the posterior fourchette (Salazar-Martinez et al., 2004) or the clitoris (Sathyanarayana et al., 2010) in women, and to the base of the clitoris in dairy cows (Gobikrushanth et al., 2017). Prenatal exposure of female fetuses to excess androgen leads to androgenization of the reproductive system in utero (Bowman et al., 2003; Sadler, 2012), which results in greater AGD and poor postnatal fertility outcomes in mice (Zehr et al., 2001), rabbits (Bánszegi et al., 2012), gilts (Drickamer et al., 1997), and women (Mendiola et al., 2012; Mira-Escolano et al., 2014a; Wu et al., 2017).

A reproductive phenotype that has high variability, repeatability, and heritability, and strong associations with fertility would be an ideal candidate for genetic selection to improve reproductive performance in dairy cows. Recently, we reported for the first time that 
AGD was normally distributed, highly variable, minimally influenced by postnatal factors such as age and height, and inversely related to pregnancy to first and subsequent insemination events in first- and secondparity Canadian Holsteins cows (Gobikrushanth et al., 2017). In this regard, first- and second-parity Canadian Holstein cows with long AGD (>127.1 mm) had lower conception rate to first AI (first parity: 30.9 vs. $53.6 \%$; second parity: 28.3 vs. $44.4 \%$ ) and decreased likelihood of pregnancy by $250 \mathrm{~d}$ in milk (hazard ratio of 0.68 for first parity and 0.76 for second parity) compared with cows with short AGD $(\leq 127.1 \mathrm{~mm})$. These results were intriguing, and if an association between the simple morphologic measure of AGD and reproductive performance could be validated in diverse populations of dairy cows, AGD could become a novel fertility trait for use in future genetic selection programs in dairy cows.

In Ireland, dairy cows have been predominantly selected for improved fertility over the last 2 decades. For example, the Irish national breeding program first introduced a multitrait selection index called the Economic Breeding Index (EBI) in 2001, placing 30\% (currently $35 \%$ ) emphasis on fertility traits, which includes calving interval and survival (Irish Cattle Breeding Federation, 2017). In contrast, in Canada, a daughter fertility sub-index was introduced to the Lifetime Performance Index (LPI) in 2007, placing only $12 \%$ emphasis on fertility traits, which includes daughter fertility and herd life (currently at 21.4\%; Canadian Dairy Network, 2018). This indicates that a relatively more fertile population of cows might be present in Ireland compared with Canada. Indeed, fertility in general is greater for Holstein-Friesian cows managed in pasturebased, seasonal-calving systems such as those in Ireland (Dillon et al., 2006) and New Zealand (Macdonald at al., 2008) than for those managed under confinement systems in the United Kingdom (Pryce et al., 2004) and the United States (Norman et al., 2009). In addition, heritability of AGD and genome-wide association studies (GWAS) identifying SNP associated with phenotypic variation in AGD are novel aspects yet to be explored in dairy cows.

We hypothesized that seasonal-calving, pasture-based cows in Ireland with short AGD have greater fertility performance than cows with long AGD, as observed in Canadian Holstein cows (Gobikrushanth et al., 2017), and that SNP associated with phenotypic variation in AGD could be identified. Therefore, the objectives of this observational study were to (1) characterize the distribution and variability of AGD, (2) determine the factors associated with AGD, (3) estimate heritability for AGD, (4) identify SNP associated with phenotypic variation of $\mathrm{AGD}$, and (5) validate the association between categories of AGD and fertility in Irish Holsteins.

\section{MATERIALS AND METHODS}

\section{Animals and Management}

A cross-sectional observational study was conducted on a convenience sample of 10 dairy herds located in the province of Munster in Ireland. Herds were operating pasture-based, seasonal-calving systems that ranged in size from 41 to 274 milking cows. The study population included 1,180 Holstein Friesian cows (308, 306, and 566 first-, second-, and $\geq$ third-parity cows, respectively). All cows calved during the spring calving season of 2017. All experimental procedures involving cows were approved by the Teagasc Animal Ethics Committee and authorized by the Health Products Regulatory Authority, which is the competent authority in Ireland responsible for the implementation of European Union legislation (Directive 2010/63/EU) for the protection of animals used for scientific purposes.

\section{Determination of AGD, Age, Hip Height, $B W$, and BCS}

Anogenital distance was defined as the distance from the center of the anus to the base of the clitoris and was measured using a stainless steel digital caliper (Silverlinec, Group Silverline Ltd., Yeovil, UK). Age (yr), hip height $(\mathrm{cm}), \mathrm{BW}(\mathrm{kg})$, and BCS were determined on the day of AGD determination in a subset of 281 cows. The age of the cow at the time of AGD measurement was determined from birth records. The height at the hip (hereafter referred to as "height") was determined using a livestock measuring stick from the ground to the top of the cow's back (above the tuber coxae) by a single member of the research team who was unaware of the cow reproductive performance at the time of measurement. Body weight was measured using an electronic farm scale, and BCS was determined by the same trained person on a 1 to 5 scale system measured in increments of 0.25 units $(1=$ thin, $5=$ fat $)$ as described by Edmonson et al. (1989). Anogenital distance measurements were obtained from 1,180 cows (mean \pm SD: $225 \pm 79$ DIM) that had no apparent perineal abnormalities such as inflamed or lacerated vulva as indicators of trauma at parturition, and that were more than 2 wk post-calving at the time of AGD determination. We observed a large difference in pregnancy to first AI (P/AI) between short-and long-AGD firstparity (53.6 vs. $30.9 \%$; difference of 22.7 percentage units) and second-parity (44.4 vs. $28.3 \%$; difference of 16.1 percentage units) Canadian Holstein cows from our previous study. An a priori power analysis, based on an average difference of 19 percentage units, indicated that 93 cows were required per AGD category. 
Therefore, this study was adequately powered to test the association between AGD and reproductive performance outcomes.

\section{Definition for Interval from Calving to Mating Start Date Categories and Reproductive Variables}

All cows calved during the spring calving season of 2017, and mating by AI commenced on a fixed calendar date on each farm between April 11 and May 3, 2017. Estrus was detected using the standard reproductive management protocols within each farm, which typically involves periods of cow observation aided by use of tail paint. The total duration of the breeding season was 12 wk. Pregnancy diagnosis using transrectal ultrasound was conducted 5 to $7 \mathrm{wk}$ after the end of the breeding period, and embryo or fetus age was estimated for pregnant cows. Conception date for pregnant cows was identified using a combination of the ultrasound results and breeding records to verify the insemination event that resulted in pregnancy establishment. The 21-d submission rate was constructed by coding cows with an insemination date within the first $21 \mathrm{~d}$ after mating start date (MSD) as 1, and coding those without an insemination date within the first $21 \mathrm{~d}$ after MSD as 0 . Pregnant to first AI (P/AI) was coded as 1 if a cow was diagnosed as becoming pregnant at the first AI. Cows that (a) were diagnosed nonpregnant at the end of the breeding period or (b) had more than one $\mathrm{AI}$ and the ultrasound estimate of embryo or fetus age indicated that pregnancy was not established at first AI were allocated a P/AI of 0 . Similarly, 21-d pregnancy rate was coded as 1 if a cow with at least one AI during the first $21 \mathrm{~d}$ of the breeding period did not receive an AI following $21 \mathrm{~d}$ of breeding and was subsequently confirmed as pregnant. Cows that (a) were diagnosed nonpregnant at the end of the breeding period or (b) had an AI event after the first $21 \mathrm{~d}$ of the breeding period and the ultrasound estimate of embryo/fetus age indicated pregnancy was not established during the first $21 \mathrm{~d}$ of the breeding period were coded 0 for $21-\mathrm{d}$ pregnancy rate. Similar criteria were used for 42 -d and 84-d pregnancy rates. The total number of inseminations received during the entire breeding season was defined as "times bred."

Cows were ranked on the interval in days from calving to MSD, and categorized as early calving ( $\geq 88 \mathrm{~d}$; $\mathrm{n}=387$ ), mid calving (71 to $87 \mathrm{~d}$; $\mathrm{n}=402$ ), or late calving $(\leq 70 \mathrm{~d} ; \mathrm{n}=391)$.

\section{Genotypes, Quality Control, and Imputation}

Of the 1,180 cows with AGD information, 907 cows also had genotype information available. Genotypes for the animals were extracted from the Irish national database run by the Irish Cattle Breeding Federation (ICBF; https://www.icbf.com). These animals had been genotyped on a variety of panels depending on the genotyping service offered by ICBF at the time of genotyping. These panels include the Illumina (Illumina Inc., San Diego, CA) bovine 3K genotype panel $(\mathrm{n}=6$; SNP $=2,900)$, Illumina Low Density panel ( $\mathrm{n}$ $=156 ; \mathrm{SNP}=6,909)$, and the custom genotyping panel International Dairy and Beef (IDB) version $1(\mathrm{n}=73$; $\mathrm{SNP}=17,137)$, version $2(\mathrm{n}=578 ; \mathrm{SNP}=18,004)$, or version $3(\mathrm{n}=94 ; \mathrm{SNP}=53,450)$. All panels were designed with the objective of imputing to the highdensity panels (Berry et al., 2014a), and hence there was minimal, if any, effect of using a wide variety of genotyping panels in this study. In addition, the use of a 2-step imputation approach and a large multi-breed high-density (HD) reference population improves imputation accuracy (Brøndum et al., 2012; Khatkar et al., 2012).

All cows had a call rate $\geq 90 \%$, and only autosomal SNP, SNP with a known chromosome and position, and SNP with a call rate $\geq 90 \%$ were retained. To increase the density of the SNP panel for GWAS, imputation to the Illumina Bovine HD BeadChip was performed using FImpute2 (Sargolzaei et al., 2014). Imputation was completed using a 2-step approach, whereby all cows were first imputed to the Illumina BovineSNP50 chip using a reference population of 3,532 Holstein-Friesian BovineSNP50 genotyped cows, and subsequently imputed to HD using a multi-breed population of 5,504 HD genotyped as the reference population. After imputation, each individual had 648,572 autosomal SNP with a minor allele frequency $>0.002$ available for analysis.

\section{Statistical Analyses}

Data were analyzed using SAS software (version 9.4; SAS Institute Inc., Cary, NC). The descriptive statistics such as minimum, maximum, mean, and standard deviation (amount of dispersion indicative of variability) for AGD were determined using MEANS procedure of SAS for all cows $(n=1,180)$ and separately for cows in the first-, second-, and $\geq$ third-parity groups $(\mathrm{n}=308$, 306 , and 566, respectively).

The differences in mean AGD between first-, second-, and $\geq$ third-parity cows were tested using the GLIMMIX procedure of SAS, where AGD was modeled against parity and the effect of herd was treated as random. The associations among cow age, height, BW, BCS, and AGD were assessed by coefficient of determination $\left(\mathrm{R}^{2}\right)$ using the REG procedure of SAS. 
Table 1. Descriptive statistics for anogenital distance (AGD; mm) in Irish Holstein-Friesian cows

\begin{tabular}{lccc}
\hline AGD by group & Minimum & Maximum & Mean \pm SD \\
\hline Overall (all parities; $\mathrm{n}=1,180)$ & 86.0 & 160.0 & $119.2 \pm 11.6$ \\
In first-parity cows $(\mathrm{n}=308)$ & 86.0 & 145.0 & $115.7 \pm 10.8$ \\
In second-parity cows $(\mathrm{n}=306)$ & 89.0 & 154.0 & $117.6 \pm 10.9$ \\
In $\geq$ third-parity cows $(\mathrm{n}=566)$ & 86.0 & 160.0 & $122.0 \pm 11.6$ \\
\hline
\end{tabular}

Initially, the linear association between AGD (continuous independent variable) and $\mathrm{P} / \mathrm{AI}$ (binomial dependent variable) was tested by the logistic regression analysis using the LOGISTIC procedure of SAS. Because no significant association was found using this approach, cows were categorized into quartiles $(\mathbf{Q})$ based on AGD (Q1; 86 to $111 \mathrm{~mm} ; \mathrm{n}=311$, Q2; 112 to $120 \mathrm{~mm} ; \mathrm{n}=330 ; \mathrm{Q} 3 ; 121$ to $127 \mathrm{~mm}$; $\mathrm{n}=265$, and $\mathrm{Q} 4 ; 128$ to $160 \mathrm{~mm} ; \mathrm{n}=274)$ and the association with reproductive outcomes (21-d submission rate, $\mathrm{P} /$ AI, pregnancy rate within 21, 42, and $84 \mathrm{~d}$ after MSD, and times bred) was analyzed by using the GLIMMIX procedure of SAS. The interval from calving to MSD (early calving: $\geq 88 \mathrm{~d}$, mid calving: 71 to $87 \mathrm{~d}$, and late calving: $\leq 70 \mathrm{~d}$, respectively) and parity (first, second, and $\geq$ third) were considered fixed effects along with categories of AGD, whereas herd was considered a random effect. The model specifications included a binary distribution and logit function and an option to retrieve odds ratios. The reproductive outcomes were initially modeled against categories of AGD, interval from calving to MSD, parity, and their interactions. As none of the interactions was significant, the final model only had the categorical variables modeled against each reproductive outcome, and the effect of herd was treated as a random variable. Significant differences were reported if $P \leq 0.05$ and considered to be a tendency if $P$ $>0.05$ and $\leq 0.10$.

\section{Heritability and GWAS for AGD}

The variance component of AGD was estimated by restricted maximum likelihood in ASReml (Gilmour et al., 1995) using a univariate animal model. Fixed effects included in the models were parity (classified as first-, second-, and $\geq$ third-parity groups) and herd. Random effects included the additive genetic effect of the animal. The pedigree of all cows was traced back to the founder population where founder cows were allocated to breed groups based on breed. The pedigree consisted of 306,273 cows. Whole-genome association analysis was performed in genome-wide complex trait analysis (Yang et al., 2011) using a mixed linear model based association based on the leave-one-chromosome-

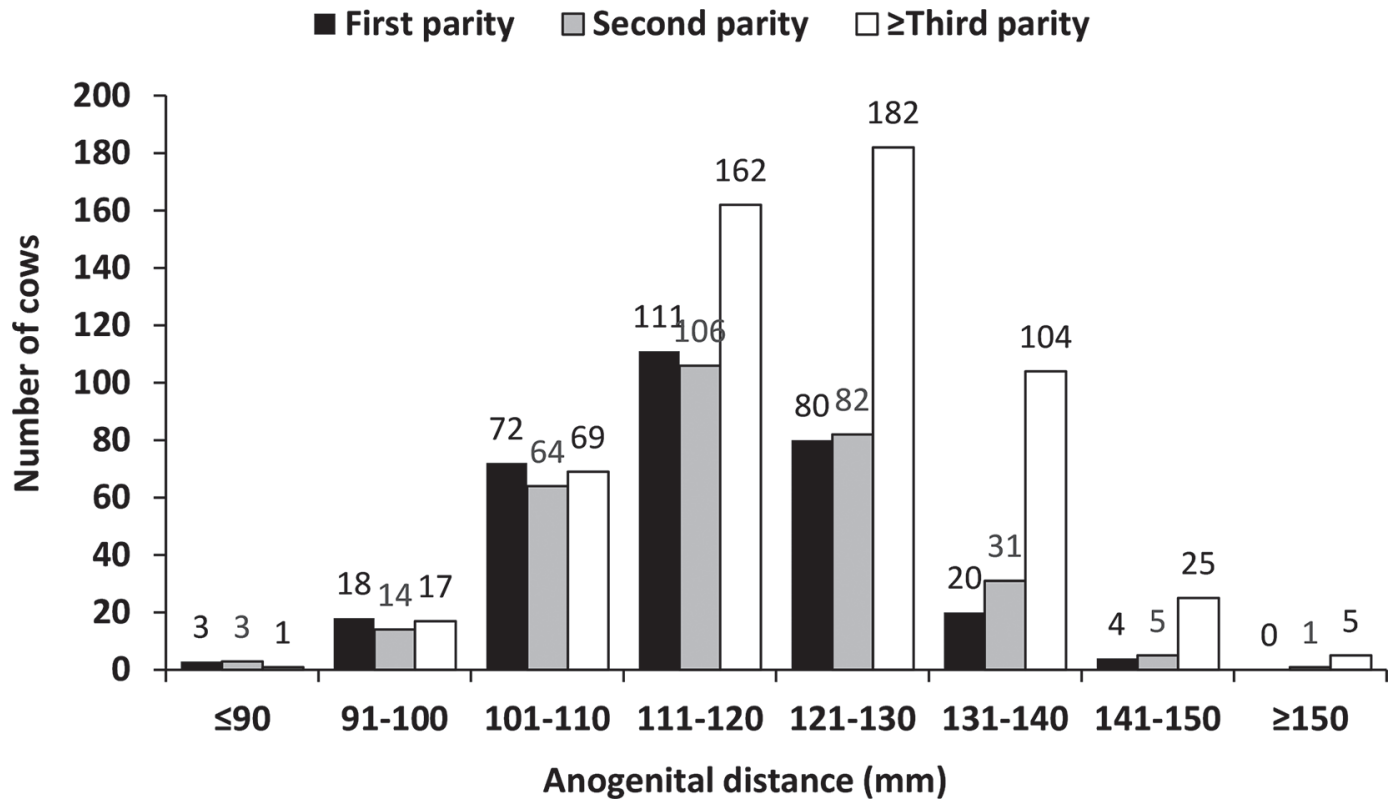

Figure 1. The distribution of anogenital distance in first- (closed bars; $\mathrm{n}=308$ ), second- (shaded bars; $\mathrm{n}=306)$ and $\geq$ third- $($ open bars; $\mathrm{n}$ $=566$ ) parity Irish Holstein-Friesian cows. 
out method (Yang et al., 2014). The following model was used: $y=\mu+\mathbf{b x}+g^{-}+e$, where $y$ is the AGD measure; $\mu$ is the overall mean; $\mathbf{b}$ is a vector of fixed effects including parity coded as first-, second-, and $\geq$ third-parity, herd identification, and the additive effect of the candidate SNP tested for association; $\mathbf{x}$ is the incidence matrix for the parameters $\mathbf{b}, g^{-}$is the accumulated polygenic effect of all SNP except those on the chromosome where the candidate SNP is located; and $e$ is the residual. False discovery rate (FDR) control was performed using the Benjamini-Hochberg method with an FDR of 0.05. Gene search was completed using Ensembl (http://ensembl.org/) and National Center for Biotechnology Information (NCBI) map viewer (https://www.ncbi.nlm.nih.gov/genome/gdv/) on the on the University of Maryland assembly of Bos taurus 3.1 genome build (UMD 3.1, College Park, MD). The relative roles of nearest candidate genes were searched using Bovine Genome Database (http://bovinegenome $. \operatorname{org} /)$.

\section{RESULTS AND DISCUSSION}

Overall, AGD had a normal distribution and high variability in Irish Holstein-Friesian cows managed under pasture-based, seasonal-calving systems (mean \pm SD: $119.2 \pm 11.6 \mathrm{~mm}$; Table 1 and Figure 1). The pattern of distribution and variability reported herein was comparable to that of our previous study (Gobikrushanth et al., 2017) in Canadian Holstein cows
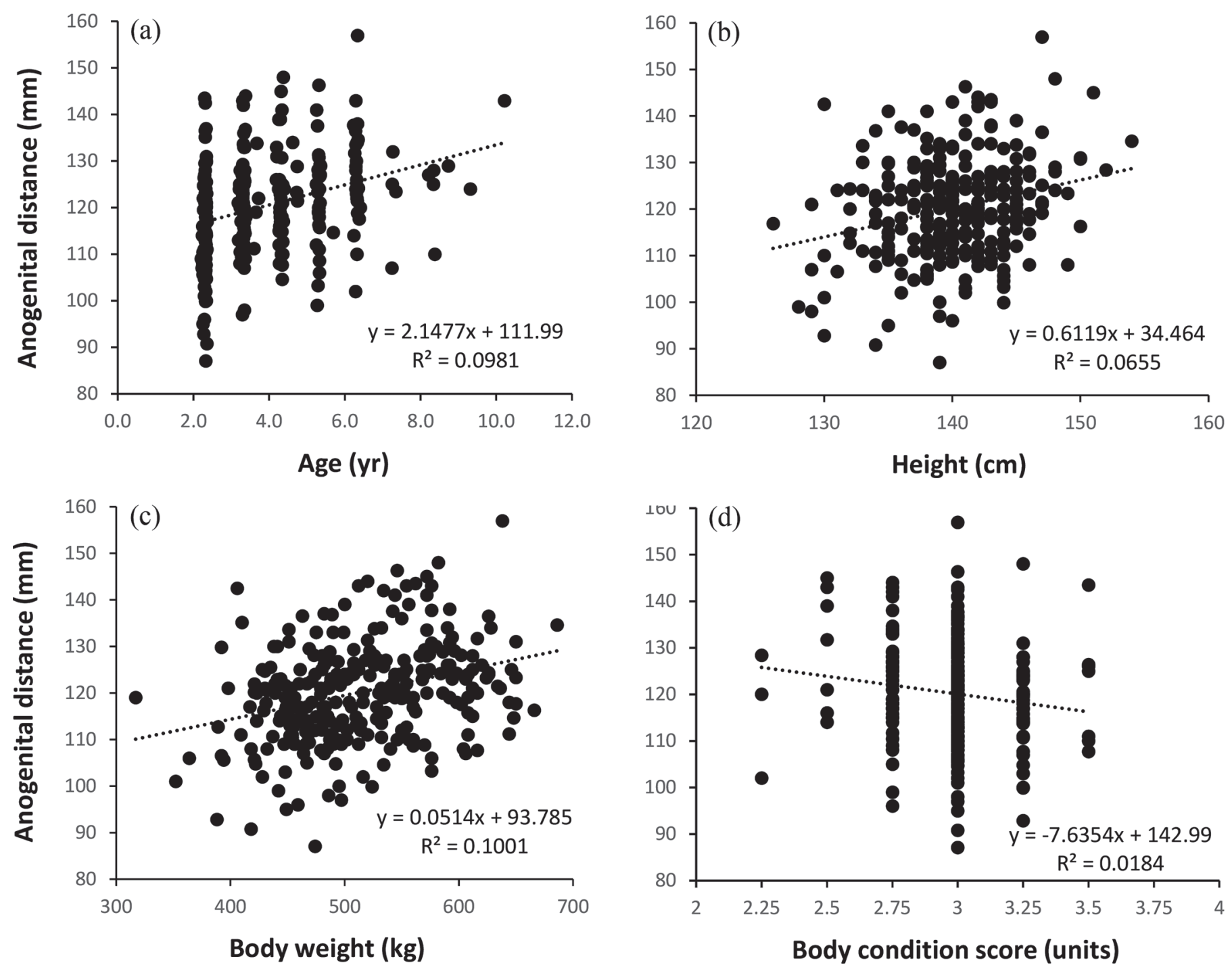

Figure 2. Association between anogenital distance and age, height at hip, BW, and BCS in a subset of 281 Irish Holstein-Friesian cows (a $\left.\mathrm{R}^{2}=0.09 ; P<0.01, \mathrm{~b} ; \mathrm{R}^{2}=0.06 ; P<0.01, \mathrm{c} ; \mathrm{R}^{2}=0.10 ; P<0.01, \mathrm{~d} ; \mathrm{R}^{2}=0.02 ; P<0.01\right)$. 
(mean \pm SD: $131.0 \pm 12.0 \mathrm{~mm}$ ) except that the overall mean AGD was $12 \mathrm{~mm}$ less in Irish Holstein-Friesian cows than in Canadian Holsteins. A large phenotypic variation for AGD (mean \pm SD: $80.4 \pm 10.5 \mathrm{~mm}$ ) also has been reported in women (Mendiola et al., 2012). The normal distribution and high variability reported for AGD in dairy cows and women indicate that large phenotypic variation exists for AGD among different species. Numerous factors could contribute to the variation of AGD in these species; therefore, we intended to identify potential postnatal factors associated with phenotypic variation of AGD in Irish Holstein-Friesian cows.

In the present study, AGD was positively associated with cow age, height, and BW, and negatively associated with BCS (Figure 2). However, the phenotypic variation in AGD explainable by these variables was small $\left(\mathrm{R}^{2}=0.09,0.06,0.10\right.$, and 0.02, respectively). In agreement with the current findings, our previous study (Gobikrushanth et al., 2017) reported that phenotypic variation in AGD was weakly associated with age $\left(\mathrm{R}^{2}=0.09\right)$ and height $\left(\mathrm{R}^{2}=0.04\right)$ in Canadian Holstein cows. Similarly, either weak or nonsignificant associations were reported between AGD and length and BW in female infants (Thankamony et al., 2009) and age, height, and BW in young women (Mendiola et al., 2012; Mira-Escolano et al., 2014b; Wu et al.,
2017). These observations indicate that the phenotypic variation in AGD is largely independent of postnatal factors, not only in women but also in dairy cows, and is likely influenced by prenatal in utero concentrations of androgens, as reported in rodents (Wolf et al., 2002; Hotchkiss et al., 2007; Dean et al., 2012). It is also possible that genotypic differences among individuals affect phenotypic AGD. Thus, we aimed to estimate heritability and identify genetic markers (SNP) associated with phenotypic variation in AGD for Irish Holstein-Friesian cows in the current study.

The heritability estimate of 0.37 (SEM: \pm 0.08 ) reported for AGD in the current study is higher than that reported for most traditional female fertility traits $(0.02$ to 0.04; Berry et al., 2014b) and closer to the heritability estimates recently reported for other reproductive phenotypes such as antral follicle count ( 0.31 by Walsh et al., 2014) and circulating anti-Müllerian hormone concentration ( 0.36 and 0.46 by Nawaz et al., 2017 and Gobikrushanth et al., 2018, respectively) in dairy cows. Although these novel reproductive phenotypes have relatively higher heritability estimates than traditional fertility traits used in the dairy industry, their relationship with fertility has been inconsistent. Identification of potential SNP associated with phenotypic variance of any trait may have the potential to increase the genomic prediction accuracy of the trait if eventually

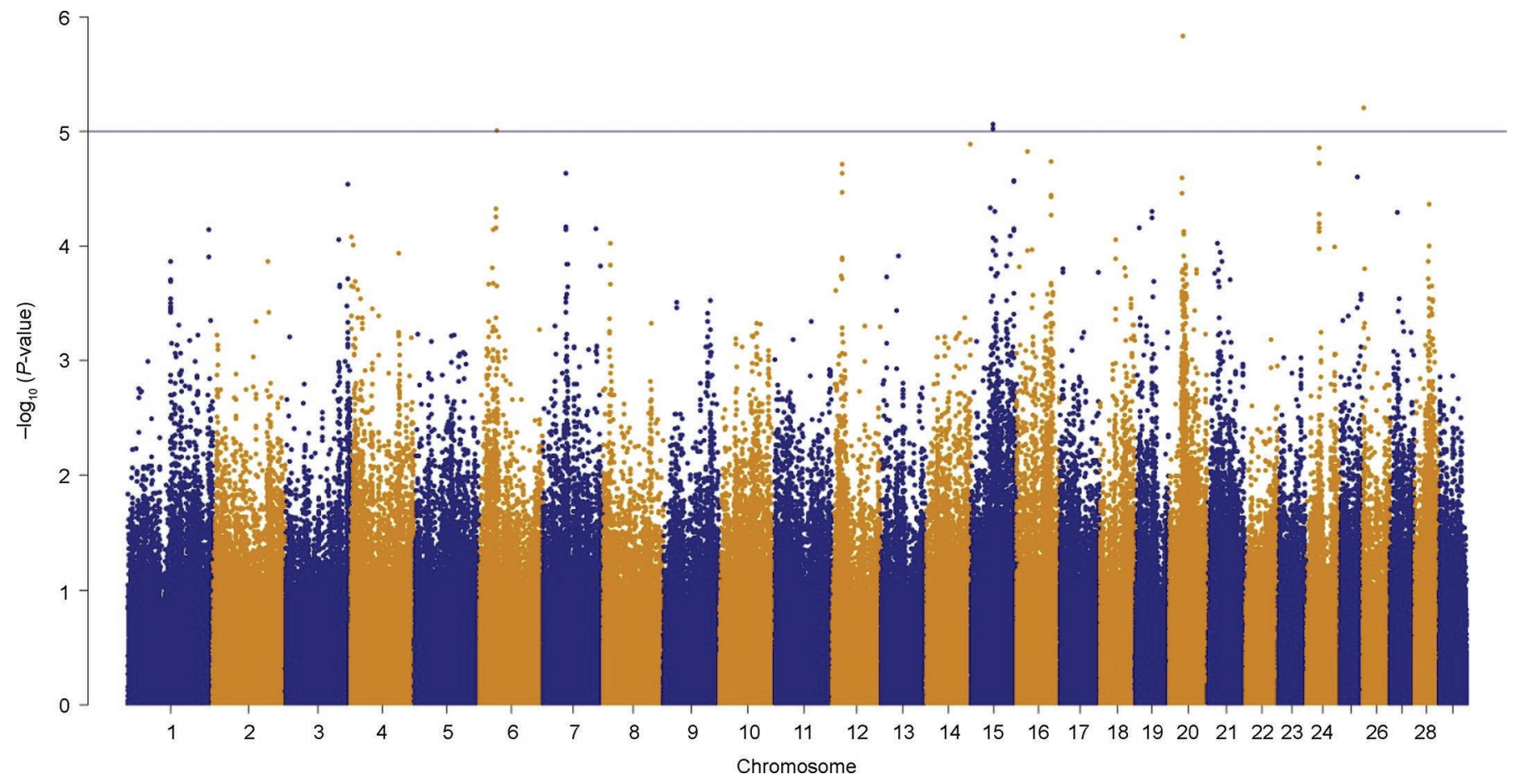

Figure 3. Manhattan plot of the genome-wide association study for anogenital distance in 908 Irish Holstein-Friesian cows. The blue horizontal line represents all SNP with a suggestive significance $(P$-value $<0.00001)$ across 4 Bos taurus autosomes (BTA 6, 15, 20, and 26). 
incorporated into SNP selection panels. However, in the current study, no SNP remained significantly associated with phenotypic variation in AGD after adjustment for multiple testing. Six SNP of suggestive significance $(P$ $<0.0001)$ were identified across 4 BTA $(6,15,20$, and 26; Figure 3). Genomic regions associated with phenotypic variation in AGD and putative candidate genes within $250 \mathrm{~kb}$ up- and downstream of the strongest association are listed in Table 2. However, none of these candidate genes is known to be related to fertility in dairy cows. Further work is necessary to examine the in utero environmental factors that influence postnatal AGD in female dairy cattle. Nevertheless, the heritability of AGD was moderately high $\left(\mathrm{R}^{2}=0.37\right)$, and thus we suggest that a previously unrecognized genetic influence on AGD also exists.

In our previous study, $\mathrm{P} / \mathrm{AI}$ and pregnancy up to 250 DIM were less for cows with long AGD compared with those with short AGD in both first- and second-parity cows (Gobikrushanth et al., 2017). Several studies have documented that females with long AGD had poorer fecundity or fertility outcomes than those with short AGD in gilts (Drickamer et al., 1997), rodents (Zehr et al., 2001), rabbits (Bánszegi et al., 2012), and women (Mendiola et al., 2012; Mira-Escolano et al., 2014a; Wu et al., 2017). Drickamer et al. (1997) reported that the AGD of newborn gilts was significantly larger in litters that had a greater proportion of male piglets. In a second experiment from the above study (Drickamer et al., 1997), using $13 \mathrm{yr}$ of data on breeding and litter composition, the authors reported that the majority of gilts from male-biased litters failed to become pregnant at the first breeding, suggesting a negative relationship between AGD and fertility in gilts. Furthermore, the onset of puberty was delayed in female mice with long AGD (Zehr et al., 2001), and rabbit does with long AGD had smaller, lighter, and more male-biased litters (Bánszegi et al., 2012). Based on these results in litter-bearing species, females fetuses exposed to a high proportion of male fetuses have longer AGD and subsequently impaired fertility in adulthood. Recent studies reported that women with longer AGD had increased follicular recruitment (Mendiola et al., 2012) and greater testosterone concentrations (Mira-Escolano et al., 2014a) during the early follicular phase and were at a much higher risk of developing polycystic ovarian syndrome (Wu et al., 2017) than those with shorter AGD. All these results lend support to our previous finding that longer AGD in Canadian Holstein cows is associated with poor reproductive performance (Gobikrushanth et al., 2017). In the present study, however, none of the reproductive variables evaluated differed significantly between AGD categories in Irish HolsteinFriesian cows (Table 3). Hence, the current results in

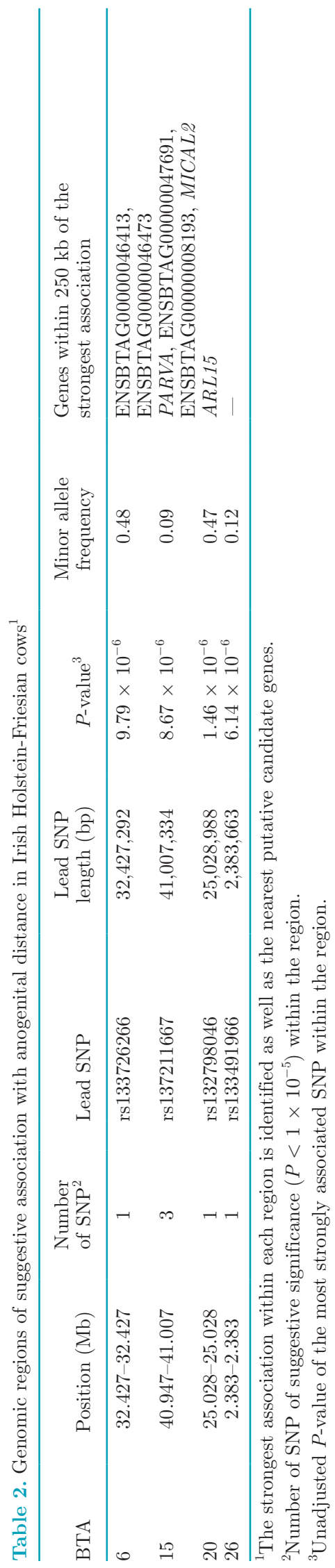


Irish Holstein-Friesian cows do not support our previous finding of an inverse relationship between AGD and fertility in Canadian Holsteins.

The inverse relationship between AGD and fertility in Canadian Holsteins was only evident in first- and second-parity cows, not in $\geq$ third-parity cows, despite the latter having phenotypic variation similar to that of first- and second-parity cows (Gobikrushanth et al., 2017). An optimum AGD of $127 \mathrm{~mm}$ was identified as being predictive of $\mathrm{P} / \mathrm{AI}$ using receiver operating characteristic curve analysis for both first- and secondparity cows with moderate sensitivity and specificity. Thus, we previously concluded that this finding was likely because only cows that excel in both fertility and milk production would typically remain in the herd beyond 2 lactations, thereby leaving a relatively fertile pool of older ( $\geq$ third parity) cows, within which the association between AGD and fertility was less evident. Extending that notion to the present study, the absence of an inverse relationship between AGD and fertility in Irish Holstein-Friesian cows is probably attributable to the strong emphasis placed on selecting for fertility traits in Ireland during the last 2 decades and aggressive culling of subfertile cows, resulting in a relatively more fertile population of cows in Ireland than in Canada. For example, overall P/AI was $55 \%$ in Irish Holstein-Friesian cows in the current study compared with $37 \%$ reported in Canadian Holstein cows in our previous study (Gobikrushanth et al., 2017). In addition, there are large differences in milk volume and composition between Irish Holstein-Friesian cows managed under pasture-based systems $(5,217 \mathrm{~kg}$ of milk, $4.22 \%$ fat, $3.53 \%$ protein; Coffey et al., 2016) and Canadian Holstein cows managed under TMR systems (10,756 kg of milk, $3.93 \%$ fat, $3.22 \%$ protein; Canadian Dairy Information Centre, 2017). Of note, as men- tioned previously, mean AGD was $12 \mathrm{~mm}$ shorter in Irish Holstein-Friesian cows compared with Canadian Holsteins (119 vs. $131 \mathrm{~mm}$, respectively) despite similar patterns of distribution and variation for AGD between these 2 populations of cows, indicating a relatively larger population of cows with short AGD in Ireland compared with Canada. In addition, the differences in the overall reproductive management system between these 2 countries could be a contributing factor. For example, in our previous study, Canadian Holstein cows were managed under a confinement system with timed $\mathrm{AI}$ as the predominant breeding method, whereas the Irish Holstein-Friesian cows in the current study were managed under a pasture-based, seasonal-calving system with AI at detected estrus being the predominant method of breeding, which may have further improved P/AI (Tenhagen et al., 2004; Thangavelu et al., 2015).

Despite the lack of relationship observed between categories of AGD and fertility in the current study, late-calving cows had poorer reproductive outcomes than mid- or early-calving cows (categorized based on the interval from calving to MSD; Table 4). Cows that have a longer interval between calving and MSD (e.g., mid- or early-calving cows) would have adequate time for uterine involution, clearance of postpartum uterine infections, and resumption of ovarian cyclicity, and have a greater number of estrous cycles before first insemination than cows that have shorter interval between calving and MSD (e.g., late-calving cows), which predisposes the former dairy cows to greater fertility performance (Thatcher and Wilcox, 1973; Galvão et al., 2004; Sheldon and Dobson, 2004; Santos et al., 2009).

In conclusion, we failed to demonstrate an inverse relationship between AGD and fertility in Irish Holstein-Friesian cows managed under a pasture-based, seasonal-calving system, despite high variability for

Table 3. Associations among anogenital distance (AGD) categories and reproductive outcomes (LSM) in Irish Holstein-Friesian cows

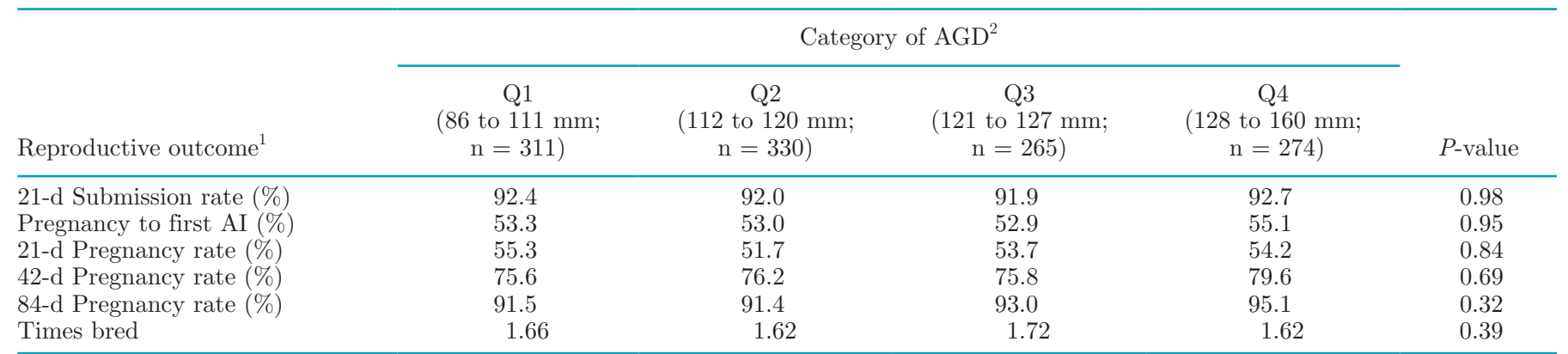

${ }^{1} 21$-d submission rate was constructed by coding cows with an insemination record within the first $21 \mathrm{~d}$ from mating start date as 1 , and cows with no insemination record within the first $21 \mathrm{~d}$ coded as 0 . Pregnancy to first AI was coded as 1 if a cow received only one insemination and was diagnosed as pregnant by the end of the breeding season. The 21-d, 42-d, and 84-d pregnancy rates were coded as 1 if cows became pregnant within 21, 42 , and $84 \mathrm{~d}$ from the mating start date, respectively, and as 0 if the animal was diagnosed as nonpregnant. Times bred $=$ total number of inseminations per cow during the 12 -wk breeding season.

${ }^{2}$ Cows were categorized into quartiles (Q) based on AGD determined at $225 \pm 79$ DIM. 
Table 4. Associations among interval from calving to mating start date categories and reproductive outcomes (LSM) in Irish Holstein-Friesian cows

Interval from calving to mating start date category ${ }^{2}$

\begin{tabular}{|c|c|c|c|c|}
\hline Reproductive outcome $^{1}$ & $\begin{array}{c}\text { Early calving } \\
(\geq 88 \mathrm{~d} ; \mathrm{n}=387)\end{array}$ & $\begin{array}{c}\text { Mid calving } \\
(71 \text { to } 87 \mathrm{~d} ; \mathrm{n}=402)\end{array}$ & $\begin{array}{c}\text { Late calving } \\
(\leq 70 \mathrm{~d} ; \mathrm{n}=391)\end{array}$ & $P$-value \\
\hline 21-d Submission rate (\%) & $88.4^{\mathrm{a}}$ & $96.5^{\mathrm{b}}$ & $88.9^{\mathrm{a}}$ & $<0.01$ \\
\hline Pregnancy to first AI (\%) & $59.4^{\mathrm{a}}$ & $56.2^{\mathrm{a}}$ & $44.7^{\mathrm{b}}$ & $<0.01$ \\
\hline 42-d Pregnancy rate $(\%)$ & $78.6^{\mathrm{a}, \mathrm{x}}$ & $80.0^{\mathrm{a}}$ & $71.2^{\mathrm{b}, \mathrm{y}}$ & $<0.01$ \\
\hline 84-d Pregnancy rate (\%) & 92.8 & 93.4 & 92.2 & 0.80 \\
\hline Times bred & $1.57^{\mathrm{a}}$ & $1.60^{\mathrm{a}}$ & $1.79^{\mathrm{b}}$ & $<0.01$ \\
\hline
\end{tabular}

$\overline{\text { ab,xy }}$ Different superscripts within the same category differed $\left({ }^{\mathrm{a}, \mathrm{b}} P<0.05\right)$ or tended to differ $\left({ }^{\mathrm{x}, \mathrm{y}} P>0.05\right.$ and $\left.\leq 0.10\right)$.

${ }^{1} 21$-d submission rate was constructed by coding cows with an insemination record within the first $21 \mathrm{~d}$ from mating start date as 1 , and cows with no insemination record within the first $21 \mathrm{~d}$ coded as 0 . Pregnancy to first AI was coded as 1 if a cow received only one insemination and was diagnosed as pregnant by the end of the breeding season. The 21-d, 42-d, and 84-d pregnancy rates were coded as 1 if cows became pregnant within 21,42 , and $84 \mathrm{~d}$ from the mating start date, respectively, and as 0 if the animal was diagnosed as nonpregnant. Times bred $=$ total number of inseminations per cow during the 12-wk breeding season.

${ }^{2}$ Cows were categorized into early calving, mid calving, and late calving based on the interval from calving to mating start date.

AGD in that population. The moderate heritability reported for AGD is promising and will remain important if an association between AGD and fertility can be established in other dairy cattle populations. Thus, the association between AGD and fertility warrants further investigation, especially in less-fertile North American dairy cattle, to corroborate our previous findings in Canadian Holstein cows.

\section{ACKNOWLEDGMENTS}

M. Gobikrushanth is a recipient of the TeagascUniversity of Alberta Walsh Fellowship sponsored by Alberta Innovates Biosolutions (Edmonton, AB, Canada). We acknowledge the staff of the Teagasc research dairies and the owners of the commercial dairy farms for their cooperation and participation in the trial. This research was partially funded by Alberta Milk (Edmonton, AB, Canada; Project no. 819413), and the Irish Department of Agriculture, Food and the Marine (Dublin, Ireland; RSF project 13S528).

\section{REFERENCES}

Bánszegi, O., P. Szenczi, D. Kriszta, A. Bilko, and V. Altbacker. 2012. Anogenital distance as a predictor of attractiveness, litter size and sex ratio of rabbit does. Physiol. Behav. 105:1226-1230.

Berry, D. P., M. C. McClure, and M. P. Mullen. 2014a. Within- and across-breed imputation of high-density genotypes in dairy and beef cattle from medium- and low-density genotypes. J. Anim. Breed. Genet. 131:165-172.

Berry, D. P., E. Wall, and J. E. Pryce. 2014b. Genetics and genomics of reproductive performance in dairy and beef cattle. Animal 8(Suppl. 1):105-121.

Bowman, C. J., N. J. Barlow, K. J. Turner, D. G. Wallace, and P. M. Foster. 2003. Effects of in utero exposure to finasteride on androgen-dependent reproductive development in the male rat. Toxicol. Sci. 74:393-406.
Brøndum, R. F., P. Ma, M. S. Lund, and G. Su. 2012. Short communication: Genotype imputation within and across Nordic cattle breeds. J. Dairy Sci. 95:6795-6800.

Canadian Dairy Information Centre. 2017. Average milk production by breed (milk recording). Accessed Jul. 22, 2018. http://www .dairyinfo.gc.ca/index_e.php?s1=dff-fcil\&s2 $=$ mrr-pcle\&s $3=\mathrm{mpb}$ -plr.

Canadian Dairy Network. 2018. Lifetime Performance Index (LPI) formula. Accessed Jul. 22, 2018. https://www.cdn.ca/document.php $? \mathrm{id}=443$

Coffey, E. L., B. Horan, R. D. Evans, and D. P. Berry. 2016. Milk production and fertility performance of Holstein, Friesian, and Jersey purebred cows and their respective crosses in seasonal-calving commercial farms. J. Dairy Sci. 99:5681-5689.

Dean, A., L. B. Smith, S. Macpherson, and R. M. Sharpe. 2012. The effect of dihydrotestosterone exposure during or prior to the masculinization programming window on reproductive development in male and female rats. Int. J. Androl. 35:330-339.

Dillon, P., D. P. Berry, R. D. Evans, F. Buckley, and B. Horan. 2006. Consequences of genetic selection for increased milk production in European seasonal pasture based systems of milk production. Livest. Sci. 99:141-158.

Drickamer, L. C., R. D. Arthur, and T. L. Rosenthal. 1997. Conception failure in swine: Importance of the sex ratio of a female's birth litter and tests of other factors. J. Anim. Sci. 75:2192-2196.

Edmonson, A. J., L. J. Lean, L. D. Weaver, T. Farver, and G. Webster. 1989. A body condition scoring chart for Holstein dairy cows. J. Dairy Sci. 72:68-78.

Galvão, K. N., J. E. P. Santos, S. O. Juchem, R. L. Cerri, A. C Coscioni, and M. Villasenor. 2004. Effect of addition of a progesterone intravaginal insert to a timed insemination protocol using estradiol cypionate on ovulation rate, pregnancy rate, and late embryonic loss in lactating dairy cows. J. Anim. Sci. 82:3508-3517.

Gilmour, A. R., R. Thompson, and B. R. Cullis. 1995. Average information REML: An efficient algorithm for variance parameters estimation in linear mixed models. Biometrics 51:1440-1450.

Gobikrushanth, M., T. C. Bruinje, M. G. Colazo, S. T. Butler, and D. J. Ambrose. 2017. Characterization of anogenital distance and its relationship to fertility in lactating Holstein cows. J. Dairy Sci. 100:9815-9823.

Gobikrushanth, M., D. C. Purfield, M. G. Colazo, S. T. Butler, Z. Wang, and D. J. Ambrose. 2018. The relationship between serum anti-Müllerian hormone (AMH) concentrations and fertility, and genome wide associations for AMH in Holstein dairy cows. J. Dairy Sci. 101:7563-7574.

Hotchkiss, A. K., C. S. Lambright, J. S. Ostby, L. Parks-Saldutti, J. G. Vandenbergh, and L. E. Gray Jr.. 2007. Prenatal testos- 
terone exposure permanently masculinizes Anogenital distance, nipple development, and reproductive tract morphology in female Sprague-Dawley rats. Toxicol. Sci. 96:335-345.

Irish Cattle Breeding Federation. 2017. What is EBI?. Accessed Jul. 22, 2018. https://www.icbf.com/wp/?p=5772.

Khatkar, M. S., G. Moser, B. J. Hayes, and H. W. Raadsma. 2012. Strategies and utility of imputed SNP genotypes for genomic analysis in dairy cattle. BMC Genomics 13:538.

Macdonald, K. A., G. A. Verkerk, B. S. Thorrold, J. E. Pryce, J. W. Penno, L. R. McNaughton, L. J. Burton, J. A. S. Lancaster, J. H. Williamson, and C. W. Holmes. 2008. A comparison of three strains of Holstein-Friesian grazed on pasture and managed under different feed allowances. J. Dairy Sci. 91:1693-1707.

Mendiola, J., M. Roca, L. Minguez-Alarcon, M. P. Mira-Escolano, J. J. Lopez-Espın, E. S. Barrett, S. H. Swan, and A. M. Torres-Cantero. 2012. Anogenital distance is related to ovarian follicular number in young Spanish women: a cross-sectional. Environ. Health 11:90.

Mira-Escolano, M. P., J. Mendiola, L. Minguez-Alarcon, M. Melgarejo, A. Cutillas-Tolin, J. J. Lopez-Espin, J. A. Noguera-Velasco, and A. M. Torres-Cantero. 2014a. Longer anogenital distance is associated with higher testosterone levels in women: A cross-sectional study. BJOG 121:1359-1364.

Mira-Escolano, M. P., J. Mendiola, L. Minguez-Alarcon, M. Roca, A. Cutillas-Tolin, J. J. Lopez-Espın, and A. M. Torres-Cantero. 2014b. Anogenital distance of women in relation to their mother's gynecological characteristics before or during pregnancy. Reprod. Biomed. Online 28:209-215.

Nawaz, M. Y., F. Jimenez-Krassel, J. P. Steibel, Y. Lu, A. Baktula, N. Vulkasinovic, S. K. DeNise, L. Neuder, J. L. H. Ireland, J. J. Ireland, and R. J. Tempelman. 2017. Genome wide association analysis and genomic heritability for AMH in Holstein dairy heifers. J. Dairy Sci. 100(Suppl. 2):132. (Abstr.)

Norman, H. D., J. R. Wright, S. M. Hubbard, R. H. Miller, and J. L. Hutchison. 2009. Reproductive status of Holstein and Jersey cows in the United States. J. Dairy Sci. 92:3517-3528.

Pryce, J. E., M. D. Royal, P. C. Garnsworthy, and I. L. Mao. 2004. Fertility in the high-producing dairy cow. Livest. Prod. Sci. $86: 125-135$.

Sadler, T. W. 2012. Chapter 16: Urogenital system. Pages 232-259 in Langman's Medical Embryology. 12th ed. The Williams \& Wilkins Company, Baltimore, MD.

Salazar-Martinez, E., P. Romano-Riquer, E. Yanez-Marquez, M. P. Longnecker, and M. Hernandez-Avila. 2004. Anogenital distance in human male and female newborns: A descriptive, cross-sectional study. Environ. Health 3:8.

Santos, J. E. P., H. M. Rutigliano, and M. F. Sa Filho. 2009. Risk factors for resumption of postpartum estrous cycles and embryonic survival in lactating dairy cows. Anim. Reprod. Sci. 110:207-221.
Sargolzaei, M., J. P. Chesnais, and F. S. Schenkel. 2014. A new approach for efficient genotype imputation using information from relatives. BMC Genomics 15:478.

Sathyanarayana, S., L. Beard, C. Zhou, and R. Grady. 2010. Measurement and correlates of anogenital distance in healthy, newborn infants. Int. J. Androl. 33:317-323.

Sheldon, I. M., and H. D. Dobson. 2004. Postpartum uterine health in cattle. Anim. Reprod. Sci. 82-83:295-306.

Tenhagen, B. A., M. Drillich, R. Surholt, and W. Heuwieser. 2004 Comparison of timed AI after synchronized ovulation to AI at estrus: Reproductive and economic considerations. J. Dairy Sci. $87: 85-94$

Thangavelu, G., M. Gobikrushanth, M. G. Colazo, and D. J. Ambrose. 2015. Pregnancy per artificial insemination and pregnancy loss in lactating dairy cows of a single herd following timed artificial insemination or insemination at detected estrus. Can. J. Anim. Sci. 95:383-388.

Thankamony, A., K. K. Ong, D. B. Dunger, C. L. Acerini, and L. A. Hughes. 2009. Anogenital distance from birth to 2 years: A population study. Environ. Health Perspect. 117:1786-1790.

Thatcher, W. W., and C. J. Wilcox. 1973. Postpartum estrus as indicator of reproductive status in the dairy cow. J. Dairy Sci. 56:608-610.

Walsh, S. W., F. Mossa, S. T. Butler, D. P. Berry, D. Scheetz, F. Jimenez-Krassel, R. J. Tempelman, F. Carter, P. Lonergan, A. C. Evans, and J. J. Ireland. 2014. Heritability and impact of environmental effects during pregnancy on antral follicle count in cattle. J. Dairy Sci. 97:4503-4511.

Wolf, C. J., A. Hotchkiss, J. S. Ostby, G. A. LeBlanc, and L. E. Gray Jr.. 2002. Effects of prenatal testosterone propionate on the sexual development of male and female rats: A dose-response study. Toxicol. Sci. 65:71-86.

Wu, Y., G. Zhong, S. Chen, C. Zheng, D. Liao, and M. Xie. 2017. Polycystic ovary syndrome is associated with anogenital distance, a marker of prenatal androgen exposure. Hum. Reprod. 32:937-943.

Yang, J., S. H. Lee, M. E. Goddard, and P. M. Visscher. 2011. GCTA A tool for genome-wide complex trait analysis. Am. J. Hum. Genet. 88:76-82.

Yang, J., N. A. Zaitlen, M. E. Goddard, P. M. Visscher, and A. L. Price. 2014. Mixed model association methods: Advantages and pitfalls. Nat. Genet. 46:100-106.

Zehr, J. L., S. E. Gans, and M. K. McClintock. 2001. Variation in reproductive traits is associated with short anogenital distance in female rats. Dev. Psychobiol. 38:229-238. 